\title{
RECIRCULATING ACCELERATOR DRIVER FOR A HIGH-POWER FREE-ELECTRON LASER: A DESIGN OVERVIEW
}

\author{
Courtlandt L. Bohn, on behalf of the Jefferson Lab FEL Team, Thomas Jefferson National \\ Accelerator Facility, Accelerator Division, 12000 Jefferson Avenue, Newport News, VA 23606
}

\section{Abstract}

Jefferson Lab is building a free-electron laser (FEL) to produce continuous-wave (cw), $\mathrm{kW}$-level light at 3-6 $\mu \mathrm{m}$ wavelength. A superconducting linac will drive the laser, generating a $5 \mathrm{~mA}$ average current, $42 \mathrm{MeV}$ energy electron beam. A transport lattice will recirculate the beam back to the linac for deceleration and conversion of about $75 \%$ of its power into if power. Bunch charge will range up to $135 \mathrm{pC}$, and bunch lengths will range down to $1 \mathrm{ps}$ in parts of the transport lattice. Accordingly, space charge in the injector and coherent synchrotron radiation in magnetic bends come into play. The machine will thus enable studying these phenomena as a precursor to designing compact accelerators of high-brightness beams. The FEL is scheduled to be installed in its own facility by 1 October 1997 . Given the short schedule, the machine design is conservative, based on modifications of the CEBAF cryomodule and MIT-Bates transport lattice. This paper surveys the machine design.

\section{INTRODUCTION}

Thomas Jefferson National Accelerator Facility (Jefferson $\mathrm{Lab}$ ) is building a cw, $\mathrm{kW}$-level, 3-6 $\mu \mathrm{m}$ free-electron laser (IRFEL, hereafter called the IR Demo). Its purpose is twofold: to assess the applicability of the technology for scaling to higher-power devices for potential industrial and defense applications, and to provide a source of intense picosecond infrared light pulses for studies of laser-solid interactions.

An FEL extracts power from a preaccelerated electron beam. Since electron-beam power scales in proportion to its energy and current, compact high-power FELs profit from high-gradient acceleration of high average current. Because superconducting if (srf) cavities accelerate beam at $\mathrm{cw}$ gradients significantly larger than normal-conducting cavities afford, and because their low surface resistances and large beam apertures are ideal for acceleration of high average current, the $\mathbb{R}$ Demo's design is based on sff technology. Moreover, wherever possible, the IR Demo incorporates technologies known to be scalable to high average power.

This paper summarizes the accelerator design and trades which lead to the chosen operating point, and it assesses key technical risks. It also provides a guide to other Conference papers that give details concerning the design.

\section{IR DEMO DESIGN}

The IR Demo, pictured in Figure 1, comprises a $10 \mathrm{MeV}$ injector and a $32 \mathrm{MeV}$ linac to produce a $42 \mathrm{MeV}, 5 \mathrm{~mA}$

electron beam for use in lasing. Beam requirements are listed in Table 1. After lasing, a high-acceptance lattice transports the electron beam back to the linac for deceleration down to $10 \mathrm{MeV}$, then to a dump. Thus, $75 \%$ of its energy is put back into if power for use in accelerating other electrons, $/ 4$ reducing if power requirements, waste heat, and radiation

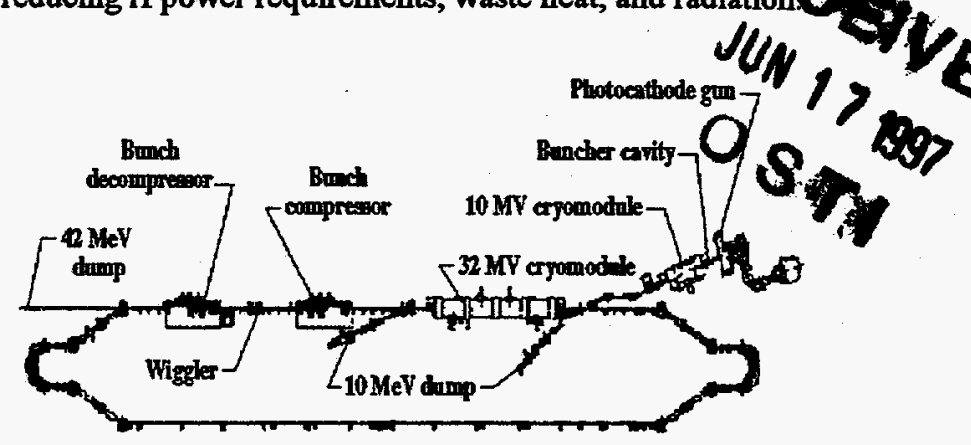

Figure 1. Schematic of IR Demo.

Table 1: Beam Requirements at Wiggler for $1 \mathrm{~kW}$ Lasing

Energy

Average current

Bunch charge

Bunch length (rms)

Peak current

Transverse emittance (normalized rms)

Energy spread (rms)

Longitudinal emittance (rms)

Pulse repetition frequency

Energy stability (rms)

Timing jitter (rms)

Current jitter (peak-to-peak)

Beam-position jitter (rms)

Beam-angle jitter (rms)

Dispersion

Horizontal betatron function (at entrance)

Vertical betatron function (at center)
$42 \mathrm{MeV}$

$5 \mathrm{~mA}$

$135 \mathrm{pC}$

$1 \mathrm{ps}$ at $135 \mathrm{pC}$

$50 \mathrm{~A}$

$13 \mathrm{~mm}$-mrad*

$210 \mathrm{keV}$

$50 \mathrm{keV}$-deg

$37.425 \mathrm{MHz}$

$4 \times 10^{-4}$

$10^{-8} / \mathrm{f}_{\mathrm{m}} * *$

$<2 \%$

$100 \mu \mathrm{m}$

$250 \mu \mathrm{rad}$

$<2 \mathrm{~cm}$

$47 \mathrm{~cm}$

$50 \mathrm{~cm}$

*allows 3rd-harmonic lasing, $20 \mathrm{~mm}$-mrad suitable for $3 \mu \mathrm{m}$. $* * f_{m}$ is the modulation frequency of the jitter.

To reduce cost and schedule, the IR Demo incorporates where possible components that are commercially available and/or are standard in Jefferson Lab's nuclear-physics accelerator (CEBAF) [1]. The injector [2] comprises a 350 $\mathrm{kV} \mathrm{cw}$ photocathode gun driven by a commercial Nd:YLF laser [3], followed by a copper buncher cavity and a CEBAFtype $1497 \mathrm{MHz}$ sff cryounit [4] to generate an average accelerating gradient of $10 \mathrm{MV} / \mathrm{m}$, boosting the beam to 10 


\section{DISCLAIMER}

This report was prepared as an account of work sponsored by an agency of the United States Government. Neither the United States Government nor any agency thereof, nor any of their employees, make any warranty, express or implied, or assumes any legal liability or responsibility for the accuracy, completeness, or usefulness of any information, apparatus, product, or process disclosed, or represents that its use would not infringe privately owned rights. Reference herein to any specific commercial product, process, or service by trade name, trademark, manufacturer, or otherwise does not necessarily constitute or imply its endorsement, recommendation, or favoring by the United States Government or any agency thereof. The views and opinions of authors expressed herein do not necessarily state or reflect those of the United States Government or any agency thereof. 


\section{DISCLAMIER}

Portions of this document may be illegible in electronic image products. Images are produced from the best available original document. 
$\mathrm{MeV}$. The accelerator uses a full CEBAF-type $1497 \mathrm{MHz}$ sif cryomodule [5] to generate an average accelerating gradient of $8 \mathrm{MV} / \mathrm{m}$, boosting the beam to $42 \mathrm{MeV}$ energy. Two commercial $50 \mathrm{~kW}$ klystrons power the injector's cryounit. A commercial wiggler [6] and modifications of CEBAF's if system, control system, and safety system are also included.

By using CEBAF-derived components, modified for high-current operation, we take advantage of Jefferson Lab's experience with building, installing, and operating the 42 cryomodules comprising its $4 \mathrm{GeV}$ accelerator [1]. Beam impingement must also be kept low $(<5 \mu \mathrm{A}$ at $>25 \mathrm{MeV})$ to mitigate radiation damage, shielding requirements, and electronic noise. Low beam loss, aided by intrinsically large apertures of sff cavities and by designing large apertures into the electron-transport system, also supports safe hands-on maintenance. The recirculation lattice is likewise based on a mature design, that used in the MIT-Bates accelerator [7].

Some simplified scaling arguments will illuminate the choice of accelerator parameters in Table 1. FEL power is just the average power in the electron beam multiplied by the average extraction efficiency and the optical cavity output coupling efficiency. Obviously each should be as high as possible to maximize the laser power.

Electron-beam power is the product of energy and current. Considerations like rf-window power handling, beam loading, cathode lifetime, and commercial availability of high-voltage power supplies led us to choose $5 \mathrm{~mA}$ for the injector's design current. A cryounit and cryomodule operating at plausible average gradients of $10 \mathrm{MeV} / \mathrm{m}$ and $8 \mathrm{MeV} / \mathrm{m}$, respectively, yield $42 \mathrm{MeV}$ energy. The average electron-beam power is therefore $210 \mathrm{~kW}$. Increasing the beam energy would deliver shorter laser wavelength but at additional cost for the accelerating structures.

The extraction efficiency is $\sim(4 N)^{-1}$, where $N$ is the number of wiggler periods [8]. Decreasing $N$ increases the extraction efficiency but also increases the energy spread of the exhaust beam and decreases the gain. The lattice can accept nominal $5 \%$ energy spread with low-loss transport [9]. The exhaust energy spread in most existing FELs is $\sim 8$ times the extraction efficiency, implying $N>40$ is desirable. We chose $N=40$ because this also provides reasonable gain.

High optical cavity output coupling efficiency is easy to achieve in the mid-IR since low-loss optical substrates and coatings are available. Low gain requires low output coupling for efficient lasing, leading to high mirror loading and low output coupling efficiency. Our goals are $>30 \%$ small-signal gain and $>90 \%$ output coupling efficiency.

Some electrons will be in tails of the phase-space distribution and not contribute to lasing. Experience has shown that the fraction of beam which contributes to the laser is from $80 \%$ to $90 \%$. Assuming $80 \%$ is useful, an extraction efficiency of $0.625 \%$ and an output-coupling efficiency of $90 \%$ will provide $\sim \mathrm{kW}$ laser power.
The electron-beam quality required for $3 \mu \mathrm{m}$ operation follows from standard design formulas [8]. A 40-period wiggler has energy acceptance $(5 N)^{-1}=0.5 \%$. The normalized emittance must satisfy $\epsilon_{n} \leqslant \gamma \lambda_{r} / 4 \pi$ to ensure the electrons are inside the optical mode. For 42 $\mathrm{MeV}$ beam $(\gamma=83)$ and $\lambda_{\mathrm{r}}=3 \mu \mathrm{m}$, the maximum emittance is $20 \mathrm{~mm}$-mrad. For third-harmonic lasing at $1.6 \mu \mathrm{m}$ the emittance should be below $10 \mathrm{~mm}$-mrad, and also the energy spread should be below $(15 N)^{-1}=0.17 \%$. These may be difficult to achieve, but third-harmonic lasing at the $100 \mathrm{~W}$ level is feasible with an emittance of $13 \mathrm{~mm}$-mrad and an energy spread of $0.25 \%$. PARMELA simulations affirm this emittance is achievable; machine impedance and beam-breakup thresholds are also well within budget [9]. With $13 \mathrm{~mm}$-mrad emittance, a 50 A peak current provides sufficient gain for stable laser operation.

We are adapting a commercial $74.85 \mathrm{MHz}$ drive laser to $37.425 \mathrm{MHz}$ using an electro-optic modulator as a compromise between required cathode quantum efficiency, peak current, and beam quality. A lower repetition rate would produce more gain but with poorer beam quality and less margin for quantum efficiency. A higher repetition rate would provide insufficient peak current.

Beam-stability requirements were chosen to satisfy FEL stability requirements. Current and timing jitter cause laser-power fluctuations, while beam-pointing jitter can lead to laser-pointing jitter and mode-quality degradation. Energy jitter causes spectral broadening and wavelength jitter. The electron beam is matched to the intrinsic wiggler beta function in the horizontal direction and is matched to the optical-mode profile in the vertical direction.

A spreadsheet incorporating semianalytic formulas for gain and extraction efficiency and benchmarked against simulations was used to estimate performance sensitivities to critical parameters [10]. Sample results are shown in Table 2. As expected, reduced electron-beam power leads to reduced laser power. The power is much less sensitive to the emittance and non-output-coupling losses in the optical cavity. The gain is relatively insensitive to most design parameters with the exception of peak current.

Table 2: Sensitivities to Critical Parameters (at $\lambda_{\mathrm{r}}=3 \mu \mathrm{m}$ )

$\begin{array}{lllll}\text { Parameter } & \text { Degradation* } & & \text { Power } & \text { Gain } \\ \text { e-beam energy** } & -10 \% & & -10 \% & \text { small rise } \\ \text { average current } & -25 \% & & -25 \% & 0 \% \\ \text { emittance } & +25 \% & & -2 \% & -14 \% \\ \text { output cavity loss } & +50 \% & & -4 \% & 0 \%\end{array}$

* Represents plausible deviations.

** $10 \%$ energy degradation yields $20 \%$ longer wavelength.

Given the design for energy recovery with low beam loss, instabilities arising from fluctuations of the cavity fields are a concern. Energy changes can cause beam loss 
on apertures or phase oscillations during beam transport with concomitant changes in the beam-induced voltage in the cavities that can lead to unstable variations in the accelerating field. An analytic model of the instabilities, including amplitude and phase feedback, and numerical simulations both suggest that, given microphonic noise of amplitude typically found in CEBAF, the if control system appears to be adequate for stable and robust operation [11].

\section{TECHINICAL RISKS AND PLANS}

Principal technical risks are operation of the highbrightness injector and achievement of energy recovery from the high-power electron beam while lasing. Space charge is important along the injector beamline, and the cryounit will be heavily beam-loaded. If necessary, the injector can be operated at twice the planned pulserepetition rate and half the charge per bunch to mitigate space-charge effects [12]. If cathode lifetime becomes a concern, an alternative cathode or cathode-preparation procedure can be used. Though energy recovery has been demonstrated experimentally [13], the approach has never been implemented with high-power beam. A scraper is located in the first leg of the first recirculation bend as a precaution against beam loss. Specifications were established that permit the scraper to serve as an excellent energy-distribution and halo diagnostic, in addition to being a safeguard for machine protection.

Coherent synchrotron radiation (CSR) will be present in the magnetic bends and potentially cause growth in the transverse emittance [14]. Estimates indicate growths of about $10 \%$ in each optical chicane surrounding the wiggler, and about $50 \%$ in each recirculation bend [15]. Concerns about CSR-induced beam degradation motivated placement of the wiggler at the exit of the linac rather than following the first recirculation bend, resulting in a correspondingly larger machine footprint. However, the calculations carry considerable uncertainty, and the machine is an ideal platform for CSR experiments. Parametric studies of emittance growth in the bunch decompressor following the wiggler and in the first recirculation arc are planned. Stringent beam requirements and plans to study CSR and space charge necessitate extensive diagnostics for commissioning and operating the IR Demo [16].

The wiggler location also permits early first light, i.e., $5 \mu \mathrm{m}$ light at $\sim 100 \mathrm{~W} \mathrm{cw}$ power without energy recovery using a $1.1 \mathrm{~mA}$ beam. The $\mathbb{R}$ Demo will incorporate an upgraded power supply for the klystrons driving the cryomodule, thus enabling them to run at $8 \mathrm{~kW}$ rather than their $5 \mathrm{~kW}$ CEBAF specification. Moreover, the wiggler placement establishes symmetry in the recirculation arcs and back leg, simplifying energy recovery [7].

Construction is scheduled to be complete by $30 \mathrm{Sep}$ 97, with commissioning to start on 1 Oct 97. Target dates are: early 1998 for initial data on CSR, spring 1998 for first light, and summer 1998 for high-power operation. While turning on the machine, we will no doubt learn much about producing and transporting high-brightness electron beams.

This work was supported by the U. S. Department of Energy under contract DE-AC05-84-ER40150, the Office of Naval Research, the Commonwealth of Virginia, and the Laser Processing Consortium.

\section{REFERENCES}

[1] H. Grunder, Proc. 1995 Part. Accel. Conf., IEEE Cat. No. 95CH35843, 1-3 (1996); A. Hutton, "Operation of CEBAF with Heavy Beam Loading", these Proceedings.

[2] H. Liu, J. Benesch, S. Benson, J. Bisognano, D. Douglas, G. Neil, D. Neuffer, C. Sinclair, B. Yunn, Nucl. Instrum. and Meth. in Phys. Rsch. A, 358, 475-478 (1995). [3] D. Engwall, C. Bohn, L. Cardman, B. Dunham, D. Kehne, R. Legg, H. Liu, G. Neil, M. Shinn, C. Sinclair, "A High-DC-Voltage GaAs Photoemission Gun: Transverse Emittance and Momentum Spread Measurements", these Proceedings.

[4] M. Wiseman, J. Preble, D. Machie, J. Fisher, J. Benesch, L. Phillips, J. Mammosser, "Jefferson Lab IRFEL Injector Cryounit Modifications and Test Results", these Proceedings.

[5] CEBAF Design Handbook (Revised), 14 January 1991. [6] D. C. Quimby, S. C. Gottschalk, F. E. James, K. E. Robinson, Nucl. Instrum. and Meth. in Phys. Rsch. A, 259, 304-311 (1987).

[7] D. Douglas, "Lattice Design for a High-Power Infrared FEL", and J. Karn, G. Biallas, A. Guerra, L. Harwood, "Magnetic Measurements of the Prototype Dipole for the IRFEL at the Thomas Jefferson National Accelerator Facility", these Proceedings.

[8] C. A. Brau, Free-Electron Lasers (Academic Press, Inc., San Diego, 1990).

[9] B. Yunn, private communication.

[10] S. Benson, private communication.

[11] L. Merminga, J. Bisognano, J. Delayen, "Energy Stability in Recirculating, Energy-Recovering Linacs in the Presence of an FEL," Proceedings 1996 EPAC.

[12] K. Jordan, R Evans, O. Garza, R. Hill, M. Shinn, J. Song, D. Venhaus, "Pulse Selection Control for the IRFEL Photocathode Drive Laser", these Proceedings.

[13] N. Sereno, $\mathrm{Ph}$. D. Dissertation, University of Illinois, 1994; T. Smith, Nucl. Instrum. and Meth. in Phys. Rsch. A, 259, 1 (1987).

[14] R. Li, C. L. Bohn, J. J. Bisognano, "Shielding Effect on the Transient Self-Interaction of a Bunch Entering a Bend", these Proceedings.

[15] C. L. Bohn, R. Li, J. J. Bisognano, "Emittance Growth from Transient Coherent Synchrotron Radiation", Proc. 1996 FEL Conf., Rome, Italy, 21-25 August 1996 (in press).

[16] G. Kraff, K. Jordan, D. Kehne, J.-C. Denard, P. Piot, S. Benson, E. Feldl, J. Song, R Ursic, "Electron-Beam Diagnostics for Jefferson Lab's High-Power Free-Electron Laser", and P. Piot, J. Song, R. Li, G. Krafft, D. Kehne, K. Jordan, E. Feldl, J.-C. Denard, "A Multislit TransverseEmittance Diagnostic for Space-Charge-Dominated Beams", these Proceedings. 